\title{
Gelişmeleri Kaçırma Korkusu ve Problemli İnternet Kullanımı Arasındaki İlişki
}

\author{
The Relationship between Fear of Missing Out and \\ Problematic Internet Use
}

\author{
Derya ORHAN GÖKSÜN*
}

Öz: Problemli internet kullanımı (PİK) alanyazında tanımlanmış en kapsamlı siber/dijital problemli davranışlardan biridir. Alanyazında sıklıkla PİK ile internet bağımlılığı, patolojik internet kullanımı ve aşırı internet kullanımı kavramları ile eş anlamlı kullanımları ile karşılaşılmaktadır. En genel anlamda PİK kişisel günlük yaşama zarar verecek ölçüde, mesleki, sosyal ya da kişisel anlamda olumsuz sonuçlar doğurabilecek kullanım olarak tanımlanmıştır. Sosyal medyanın yaygınlaşması ile günlük yaşamın bir parçası durumuna gelen başta genç bireyler olmak üzere sosyal ağ kullanıcılarının sürekli bir izleme ve güncelleme davranışı, sosyal bağlamda başkalarının kendisi olmadan daha iyi vakit geçirdiği kaygısı ise gelişmeleri kaçırma korkusu (GKK) olarak tanımlanmıştır. GKK'nun yoksunluk, sevilme gereksiniminin çevrimiçi ortamlarda karşılanması gibi göstergeleri internet kullanımı gerektirdiği ve problemli davranış olarak tanımlanabildiğinden, PİK ile benzerlik gösterdiği söylenebilir. Bu çalışmanın temel amacı GKK ve PİK arasındaki ilişkiyi ortaya çıkarmak ve GKK'nun bir PİK alt boyutu olup olmadığını kanıtlamaktır. Çalışma kapsamında PİK ve GKK ölçekleri ile2017-2018 eğitim öğretim yılı Bahar yarıyılında Türkiye'de bir devlet üniversitesinin çeşitli fakültelerinde öğrenim görmekte olan 538 üniversite öğrencisinden veri toplanmıştır. Toplanan veriler Pearson korelasyon katsayısı incelenerek ve yapısal eşitlik modellemesi kullanılarak analiz edilmiştir. Araştırma kapsamında elde edilen sonuçlardan ilki GKK'nun PİK'nın alt boyutlarının tamamı ile anlamlı ve pozitif yönde ilişkilerinin olduğudur. Çalışma kapsamında elde edilen bir diğer sonuç GKK'nun PİK'nın bir alt boyutu olarak düşünülebileceğidir. Bu durum doğrulayıcı faktör analizi ile iki ölçeğin maddelerinin birlikte tek ölçek gibi faktör yapısı olabileceği düşünüldüğünde anlamlı bir yapının ortaya çıktığı bulgusu ile ortaya konmuştur $\left(\chi^{2} / \mathrm{sd}=2.19\right.$, $\mathrm{p}<0.001, \mathrm{RMSEA}=0.06, \mathrm{SRMR}=0.07, \mathrm{NFI}=0.95, \mathrm{CFI}=0.97, \mathrm{GFI}=0.80)$. Elde edilen bu sonuçlar alanyazında yürütülen benzer çalışmalar ile tartışılmıştır.

Anahtar Kelimeler: Gelişmeleri kaçırma korkusu, problemli internet kullanımı, sosyal medya, bağımlılık

\begin{abstract}
Problematic internet use (PIU) is one of the most comprehensive cyber/digital behavioral concepts in literature. Internet addiction, pathological internet use, excessive internet use concepts are frequently used as synonymous with PIU. In general, PIU was defined as using internet in a detrimental way during daily, personal professional and social activities. Along with social media tools became widespread, the following and updating frequentative behaviors, the others have fun more than when they are together anxiety of social network users in particular the young was defined as fear of missing out (FoMO). FoMO and PIU share some similarities such as the need of internet connection, meeting the need of being liked in online platforms, deprivation, defining as a problematic behavior. The main purposes of this study are to reveal the relationship between FoMO and PIU and to prove whether FoMO is a sub-dimension of PIU. For this study, the data were gathered from 538 undergraduate students who were in different faculties of one of state universities in Turkey at 2017-2018 academis year spring semester via PIU and FoMO scales. The findings were created as conducted Pearson correlation analysis and structural equation modelling. First of the results is that there are significant and positive relationships among FoMO and all of the PIU sub-dimensions. The other result is that FoMO could be examined as a sub-dimension of PIU. This situation was proved via confirmatory factor analysis defined the paths of FoMO and its items as sub-dimension of PIU $\left(\chi^{2} / \mathrm{df}=2.19, \mathrm{p}<0.001, \mathrm{RMSEA}=0.06, \mathrm{SRMR}=\right.$ $0.07, \mathrm{NFI}=0.95, \mathrm{CFI}=0.97, \mathrm{GFI}=0.80)$. The obtained results were discussed and compared with previous studies.
\end{abstract}

Keywords: Fear of missing out, problematic internet use, social media, addiction

*Dr., Adıyaman Üniversitesi, Eğitim Fakültesi, Bilgisayar ve Öğretim Teknolojileri Eğitimi Bölümü, ORCID: 0000-0003-0194-0451, e-posta: dorhan@adiyaman.edu.tr 


\section{Giriş}

Hayatımıza hızla giren internet ve internet bağlantısı kullanan teknolojiler davranışlarımızda da değişikliğe yol açmıştır. Bu değişiklik olumlu ve olumsuz açılardan gerçekleşmiştir. Araştırmacılar teknolojinin etkisiyle değişen davranışlara yönelik yeni adlandırmalar ve tanımlamalar kullanmak durumunda kalmışlardır. Örneğin, yapılan araştırmalara göre eğitim alanlarında kullanılan teknolojiler, öğrenmeyi destekleme, kolaylaştırma, etkililiğini artırma, engelli bireylerin günlük yaşamlarını düzenlemede kullandıkları yardımcı teknolojiler gibi etkiler dijitalleşme öncesine göre olumlu görünürken (Sadi ve diğerleri, 2008; Sani-Bozkurt, 2017) teknoloji bağımlılığı, internet bağımlılığı, sosyal medya bağımlılığı, siber zorbalık gibi sıralanabilecek birçok davranış teknoloji ile birlikte ortaya çıkmış problemli davranışlar olarak (Leung, 2004; Li, 2006; Öztürk, Odabaşığlu, Eraslan, Genç ve Kalyoncu, 2007; Young, 1998) tanımlanmıştır. Zaman içinde sözü edilen teknolojiler üst seviyelere evrilmiş ve etkilediği davranışlar da değişime uğramıştır. Her geçen gün artan ve yığılan internet teknolojileri ve beraberinde getirdiği problemli internet kullanımı (PİK), telefon, oyun, ekran gibi bağımlılıklar ve gelişmeleri kaçırma korkusu (GKK) gibi davranışlar da çeşitli açılardan değișmiş ve zaman içinde farklı göstergeler ile belirmeye başlamıştır. Sözü edilen göstergelerin eğitim ortamlarında da gözlenmeye başlaması ile birlikte (Alt, 2015; Ceyhan, 2008; Varol ve Y1ldırım, 2017) bu problemli davranışlar eğitim-öğretim sisteminin de araştırma konularına dönüşmüşlerdir.

PİK alanyazında tanımlanmış en kapsamlı siber/dijital problemli davranışlardan biridir. Alanyazında sıklıkla PİK ile internet bağımlılığı, patolojik internet kullanımı ve aşırı internet kullanımı kavramları ile eş anlamlı kullanımları ile karşılaşılmaktadır (Chou ve Hsiao, 2000; Davis, 2001; Krishnamurthy ve Chetlapalli, 2015). İnternet bağımlılı̆ı; internete ve internette geçirilen süreye giderek daha fazla gereksinim duyma, internetle ilişkili aşırı zihinsel çaba, internette geçirilen süre azaldığında huzursuzluk, sinirlilik gibi yoksunluk belirtileri gösterme, internet aracılı̆̆ ile kumar oynama, sohbet etme, alışveriş yapma ve oyun oynama gibi durumlara bağımlılık gibi ölçütler ile tanımlanmıştır (Davis, 2001; Griffiths, 2000; Tsai ve Lin, 2001; Young, 1998). Patolojik internet kullanımı ile internet bağımlılı̆̆ını eş anlamlı kullanan Davis (2001) belirli internet uygulamalarını aşırı kullanmayı bağımlılık, özel bir amaç olmaksızın interneti aşırı kullanmayı da aşırı internet kullanımı olarak birbirinden ayrılmaktadır. PİK ise kişisel günlük yaşamına zarar verecek ölçüde, mesleki, sosyal ya da kişisel anlamda olumsuz sonuçlar doğurabilecek kullanım olarak tanımlanmıştır (Spraggins, 2009). PİK; ilk konuşulmaya başlandığı dönemler olan 1900lü yılların sonundan günümüze kadar olan süreçte çerçevesini giderek genişletmiş bir olgu olarak karşımıza çıkmaktadır. Başlangıçta PİK, teknoloji bağımlılığı, internet bağımlılığı, sanal kumar gibi problemli davranışlar ile açıklanmıştır (Davis, 2001; Griffiths, 1996; Li ve Chung, 2006; Tsai ve Lin, 2003). Ancak daha sonra bu davranışlar farklı davranış özelliklerine göre kendi içinde sınıflandırılmıştır. Örneğin teknoloji bağımlılığı akıllı telefon bağımlılığı, ekran bağımlılığı, medya bağımlılığı gibi sinıflandırılırken internet bağımlılığı kapsamında sosyal medya bağımlılığı, siber aylaklık, siber suçlar gibi birçok problemli davranış tanımlanmıştır. İnternete kolay erişim ve sosyal medya birçok problemli internet kullanımının nedeni olarak gösterilmektedir (Kuss ve Griffiths, 2011). $\mathrm{Bu}$ tanımlamalardan hareketle, kişilerin problemli internet kullanımlarını belirlemede, internet kullanım amacının ve bu kullanımın çıktılarının etkili olduğu söylenebilir. Kişiler geçmişte interneti akademik amaçlarla kullanırken günümüzde internet kullanım amaçları sosyal medya ve iletişim olmuştur (Ceyhan, 2010).

Özellikle 2003 yılında LinkedIn uygulaması ile başlayan ve 2004 yılında Facebook'un kurulması ile yaygınlaşan sosyal medya araç ve uygulamaları (Taş, 2015) internet davranış biçimlerinin ve göstergelerinin yeniden tanımlanmasına sebep olmuştur. Sosyal ağlar bilginin hızla üretilmesi ve çok sayıda kişiye ulaştırılmasını sağlamakta ve bu yolla bilgi yoğunluğunun artmasına yol açmıştır. Bu durum başta genç bireyler olmak üzere sosyal ağ kullanıcılarının sürekli bir izleme ve güncelleme davranışı sergilemesine neden olmuştur. Sosyal medya ile birlikte oluşan bu davranış alanyazında GKK olarak adlandırılmıştır (Hato, 2013; Przybylski, Murayama, DeHaan ve Gladwell, 2013). İlk kez Morford (2010) tarafindan kullanılan bu kavram; bireylerin birbirleri ile bağlantı kurma gereksinimini karşılamada kullandıkları sosyal 
medyada yapılan paylaşımları kaçırmak istememeleri olarak tanımlanmıştır. Bireylerin ilişkilerine yönelik kaygılarının attığı dönemde sosyal medyaya yöneldikleri ve başkalarının kendisi olmadan iyi vakit geçirdiklerine yönelik bir korku olarak da tanımlanabilir (Blackwell, Leaman, Tramposch, Osborne ve Liss 2017). Bu korku kişinin sosyal bağlamda dişlanmışlık gibi olumsuz duygulara kapılmasına ve başkalarının sosyal yaşamına imrenme ya da kıskanmasına neden olmaktadır (Hetz, Dawson ve Cullen, 2015; Reagle, 2015). Sözü edilen bu duygu ve davranışlar GKK'nun bir problemli davranış olduğunun göstergesidir. GKK internet kullanımı ile ortaya çıkan bir problemli davranış olduğundan PİK çerçevesinde incelenebileceği düşünülmektedir. Daha açık bir ifade ile GKK göstergeleri internet kullanımı gerektirdiği ve problemli davranış olarak tanımlanabildiğinden, PİK ile benzerlik gösterdiği söylenebilir.

GKK'nun, bireylerin günlük yaşamlarında eksik olduğunu düşündükleri sevilme ve ilgilenilme gereksinimlerinin, sosyal medya paylaşımları ile tamamlamaya çalışmaları, sosyal ağlar dışında geçirdikleri zamanlarda yalnız hissetmeleri gibi göstergeleri de bulunmaktadır (Dossey, 2014). Alanyazında GKK'nın sadece sosyal medya kullanımı ile değil, aynı zamanda takıntılı ve sağlıksız davranışlarla, problemli ve bağımlı internet kullanımları ile ilişkili olduğu (Stead ve Bibby, 2017) ifade edilmiştir. PİK için kullanılan internet olmadığ durumlarda yoksunluk belirtileri gösterme durumu göz önüne alındığında, GKK ve PİK arasındaki ilişki açıkça görülmektedir. Ancak alanyazında, bu ilişkiyi istatistiksel olarak doğrudan kanıtlayan bir çalışmaya rastlanmamıştır. Bununla birlikte GKK ve PİK tanımlamaları 1şı̆̆ında, GKK'nun birçok noktada PİK ile benzer göstergeler ile açığa çıktığı görülmektedir. Bu noktalardan bazıları internet kullanımı, bağlantı olmadığı durumlarda yoksunluk belirtileri, yalnızlık hissi olarak sıralanabilir. Bu benzer göstergeler dışında PİK yalnızca aşırı sosyal medya kullanımı ile sınırlandırılmamaktadır. Kumar, uygunsuz içerikleri yayma, siber zorbalık gibi siber suçlar,siber aylaklık, aşırı çevrimiçi alışveriş gibi olumsuz göstergeleri olan durumlar da birer PİK kapsamında gözlemlenen davranıştır. Bu bilgiler doğrultusundaPIK'nın GKK'nu kapsayan bir şemsiye kavram olup olmadığ 1 , başka bir deyişle GKK'nun PİK'nın bir alt boyutu olup olmadığ1 sorusu akla gelmektedir. Sözü edilen bu ilişkiyi istatistiksel olarak kanıtlayan bir çalışma bulunamamıştır. Bu durum ile ilgili alanyazındaki bulgu eksikliğini giderebilmek amacı ile yürütülen bu çalışmanın genel çerçevesi ve temel amacı GKK ve PİK arasındaki kuramsal ilişkiyi belirlemektir. Bu amaçla aşağıda sıralanan araştırma sorularına yanıt aranmıştır.

1. GKK ile PİK arasında anlamlı bir ilişki var mıdır, varsa bu ilişkinin yönü ve düzeyi nedir?

2. GKK, PİK'nın bir alt boyutu olarak anlamlı mıdır?

\section{Yöntem}

Bu bölümde araştırmanın desenine, katılımcılarına, veri toplama araçlarına ve verilerin analizine yönelik bilgiler yer almaktadır.

\section{Araştırmanın deseni}

Araştırma sürecinde nicel araştırma desenlerinden ilişkisel tarama desenine başvurulmuştur. İlişkisel tarama, birden fazla değişken arasındaki ilişkinin test edilerek ortaya çıkarılmasını amaçlamaktadır (Büyüköztürk, Kılıç Çakmak, Akgün, Karadeniz ve Demirel, 2018, s. 16; Sönmez ve Alacapınar, 2013, s. 48). Bu çalışmada, GKK ve PİK arasındaki ilişkiye ve bu ilişkinin boyutlarını ortaya çıkarmaya yönelik araştırma sorularına yanıt aranmıştır. Buradan yola çıkılarak araştırma sorularının her biri için ilişkisel tarama deseni işe koşularak veriler toplanmıştır.

\section{Örneklem/çalışma grubu}

Araştırmanın konusu gereği araştırmanın genel evrenini internet kullanan ve sosyal medyayı takip eden bireyler oluşturmaktadır. Veri toplama araçlarının geliştirildiği hedef kitle göz önünde bulundurularak bu genel evren üniversite öğrencileri ile sınırlandırılarak araştırma evreni belirlenmiştir. Söz konusu araştırma evrenin tamamında çalışma olanağı olmadığından araştırma verilerinin toplandığ 1 katılımcıların belirlenmesinde örnekleme yoluna gidilmiştir. 
Evrenin tamamı göz önünde bulundurularak, gerek üniversitelerin öğrencilerine sağladığ olanaklar gerekse mobil erişimin kolaylığı açısından üniversite öğrencilerinin internet erişim problemi yaşanmadığı düşünülmektedir. Bu açıdan araştırmanın konusu olan GKK ve PİK bağlamında evrenin homojen olduğu düşünülmektedir.

GKK ve PİK ölçekleri, konunun doğası gereği araştırmacıların samimi yanıt vermeme olasılığı olan maddeler içermektedirler. $\mathrm{Bu}$ nedenle çalışmanın veri toplama sürecinde katılımcıların konu ile ilgili samimi yanıt vermelerinin sağlanması amacı ile etik problem yaşamayacaklarının garanti edilmesi, kimlik bilgilerinin açığa çıkarılmayacağına inandırılmaları gibi noktalarda önlemler alınması gerekmiştir. Araştırmacının veri toplama süreçlerini şahsen yürütebilmesi sözü edilen gerekçeden dolayı önemli olduğu düşünülmüştür. Ek olarak veri toplama ekonomikliği ve öğrenim gördükleri fakültelerin çeşitlendirilmesi araştırmanın evrene genellenebilirlik durumunu artırılması dış geçerlik bağlamında da kolaylık sağlayacağından araştırmada kolayda örnekleme tekniğine başvurulmuştur. Kolayda örnekleme; araştırmaya hız ve uygulama kolaylığı sağlayan, veri toplama aracını yanıtlayan herkesin araştırmaya dâhil edildiği bir örnekleme tekniğidir (Altunışık, Coşkun, Bayraktaroğlu ve Yıldırım, 2012, s. 142). $\mathrm{Bu}$ teknik ile belirlenen araştırmanın katılımcılarını 2017-2018 eğitim öğretim yılı Bahar yarıyılında Türkiye'de bir devlet üniversitesinin çeşitli fakültelerinde öğrenim görmekte olan 538 öğrenci oluşturmaktadır. Katılımcıların dağılımı Tablo 1'de sunulmuştur.

Tablo 1.

Araştırmanın Katılımcılarının Demografik Özelliklerine Göre Dağılımı

\begin{tabular}{|c|c|c|c|}
\hline \multicolumn{2}{|c|}{ Dağılım değişkeni } & $f$ & Dağılım oranı (\%) \\
\hline \multirow[t]{3}{*}{ Cinsiyet } & Kadın & 341 & 63,4 \\
\hline & Erkek & 186 & 34,6 \\
\hline & Belirtilmeyen & 11 & 2,00 \\
\hline \multirow{6}{*}{$\begin{array}{l}\text { Öğrenim } \\
\text { görmekte } \\
\text { olduğu fakülte }\end{array}$} & Eğitim & 123 & 22,9 \\
\hline & Fen & 104 & 19,3 \\
\hline & İktisat & 103 & 19,1 \\
\hline & Mühendislik & 73 & 13,6 \\
\hline & Sağlık & 59 & 11,0 \\
\hline & Turizm & 76 & 14,1 \\
\hline \multirow[t]{5}{*}{ Sinif } & 1. sinif & 85 & 15,8 \\
\hline & 2. sinif & 259 & 48,1 \\
\hline & 3. sinif & 115 & 21,4 \\
\hline & 4. sinif & 76 & 14,1 \\
\hline & Belirtilmeyen & 3 & 0,6 \\
\hline \multirow{5}{*}{$\begin{array}{l}\text { Akademik } \\
\text { genel not } \\
\text { ortalamas1 }\end{array}$} & $0,01-1,00$ & 4 & 0,7 \\
\hline & $1,01-2,00$ & 51 & 9,5 \\
\hline & $2,01-3,00$ & 343 & 63,8 \\
\hline & $3,01-4,00$ & 130 & 24,2 \\
\hline & Belirtilmeyen & 10 & 1,9 \\
\hline \multicolumn{2}{|l|}{ Toplam } & 538 & 100,0 \\
\hline
\end{tabular}

Tablo 1'de sunulduğu gibi araştırmaya çeşitli fakültelerin çeşitli sınıflarında öğrenim görmekte olan 538 üniversite öğrencisi katılmıştır. Katılımcıların çeşitli demografik değişken açısından çeşitlendirilmiş olması araştırma kapsamında evrene genellenebilir bir örnekleme ulaşıldığının bir göstergesi sayılabilir. Veri toplama süreci araştırmacı tarafından yürütülmüş ve katılımcıların gönüllü katılımı sağlanmıştır. Bu bağlamda elde edilen verilerin katılımcıların gerçek görüşleri olduğu varsayılabilir.

\section{Veri toplama}


Araştırmanın verileri Ceyhan, Ceyhan ve Gürcan (2007) tarafindan geliştirilen PİK ve Przybylski ve diğerleri (2013) tarafindan geliştirilen Gökler, Aydın, Ünal ve Metintaş (2016) tarafından Türkçeye uyarlanan GKK ölçekleri ile toplanmıştır. Ceyhan ve diğerleri (2007) tarafindan geliştirilen PİK ölçeği interneti haftada en az iki saat kullanan 1658 üniversite öğrencisinin katılımı ile geliştirilmiş̧tir. Ölçek "Tamamen uygun" ile "Tamamen uygun değil" seçenekleri arasında dağılan beşli likert tipinde yanıtlanmaktadır. "İnternetin olumsuz sonuçları", "Sosyal fayda/sosyal rahatlık", "Aşırı kullanım" olarak adlandırılan üç faktör altında 33 maddeden oluşmakta ve toplam varyansı \%48,96 oranında açıklamaktadır $(0,93<\alpha<0,94)$. Gökler ve diğerleri (2016) tarafindan Türkçeleştirilen GKK ölçeğinin geçerlik ve güvenirlik çalışmalarının katılımcıları internet kullanan ve 18 yaşından büyük 200 üniversite öğrencisidir. Ölçek faktör altında 10 maddeden oluşmakta $(\alpha=0,81)$ ve toplam varyansın \%39'unu açıklamaktadır. Sözü edilen ölçekler katılımcıların cinsiyet, fakülte, sınıf ve akademik not ortalamalarının sorulduğu demografik bilgi formu ile birlikte tek forma basılarak araştırmanın bulgularını oluşturan veriler toplanmıştır.

Veri toplama süreci araştırmacı tarafından yürütülmüştür. Bu yolla katılımcılara etik konular hakkında bilgilendirme yapılmış ve araştırmaya katılmanın gönüllülük esasına dayandırılması sağlanmıştır. Veri toplama aracını doldurmayı kabul eden katılımcılara basılı formlar dağıtılmış ve yine araştırmacı tarafindan toplanarak veri seti haline getirilmiştir. Sürecin tek elden yürütülmesi ile katılımcı verilerinin gizliliği garanti edilmiş̧tir.

\section{Verilerin analizi}

Verilerin analiz süreci araştırmanın alt soruları çerçevesinde şekillendirilmiştir. İlk araştırma sorusunun yanıtlanmasında Pearson momentler çarpımı korelasyon katsayısına başvurulmuştur. Araştırmaya konu olan değişkenlerin sürekli olduğu ve normal dağıldığı durumlarda ilişki hesaplanmasında bu katsayıya başvurulmaktadır (Özdamar, 2013, s. 406; Şencan, 2005). Araştırma kapsamında veri toplanan araçlar geçerli ve güvenilir ölçekler olduğundan toplan puan alınabilmekte ve bu puan sürekli değişken kategorisinde değerlendirilebilmektedir. Sürekli değişkenlerin normal dağılımlarının belirlenmesinde, Shapiro-Wilk testinin büyük örneklemlerde hatalı sonuç üretebileceğinden (Huck, 2012, s. 413) yola çıkılarak çarpıklık ve basıklık katsayıları incelenerek belirlenmiştir. Araştırma kapsamında toplanan verilerin çarpıklık katsayıları $(0,087$ ile 0,811 aralığındadır $)$ ve basıklık katsayıları $(-0,277$ ile 0,207 aralığındadır) incelenmiş ve tüm değişkenlere ilişkin değerler +1 ve -1 aralığında olduğundan (Huck, 2012, s. 27) normal dağılım varsayımının sağlandığı düşünülmüştür. Bütün bunlar 1şı̆̆ında Pearson momentler çarpımı korelasyon katsayısı önkoşulları sağlanmış ve ilk araştırma sorusu bu test ile yanıtlanmıştır.

İkinci araştırma sorunun yanıtlanmasında bir yapısal eşitlik modellemesi türü olan doğrulayıcı faktör analizine başvurulmuştur. Doğrulayıcı faktör analizi daha önceden kuramsal altyapı çerçevesinde kurgulanmış bir yapının model olarak anlamlı olup olmadığına yönelik, gözlenen değişkenler ve gizil değişkenler arasında çizilen yolların test edilmesini sağlayan bir analiz tekniğidir (Tabachnick ve Fidell, 2013, s. 686). Bu analiz değişkenler arasındaki ilişkiden yola çıkarak ampirik bulgular üretir (Çokluk, Şekercioğlu ve Büyüköztürk, 2012, s. 275). Bu nedenle korelasyon analizi için incelenen önkoşul varsayımlarının bu analiz için de gerektiği (Çokluk ve diğerleri, 2012, s. 274, 275) ve araştırma kapsamında toplanan verilerin bunları sağladığ düşünülen GKK'nun PİK'nın bir alt boyutu olup olmadığı doğrulayıcı faktör analizi ile test edilmiştir. Sözü edilen analizlerin sonuçları bu çalışmanın bulgular bölümünde raporlanmıştır.

\section{Bulgular}

Bu bölümde alt araştırma sorularının yanıtlanmasında başvurulan analiz sonuçları, alt araştırma soruları ile ilişkilendirilerek sunulmuştur. $\mathrm{Bu}$ nedenle ilk alt araştırma sorusunun yanıtlanmasında başvurulan korelasyon analizi bulguları ile ikinci alt araştırma sorusunun yanıtlanmasına yönelik doğrulayıcı faktör analizi bulguları ayrı başlıklar altında yer almaktadır.

\section{GKK ile PİK'nın Alt Boyutları Arasındaki İlişki}


GKK ile PIK'nın üç alt boyutu arasındaki ilișkinin analizi Pearson Momentler çarpımı korelasyon katsayısı ile gerçekleştirilmiştir. GKK ve PİK geçerli ve güvenilir ölçme araçları olduklarından bu ölçekler kullanılarak elde edilen veriler ile toplam puan alınabilmiş ve sürekli değiş̧kenler ile analiz yürütülmüştür. Değişken puanları normal dağıldığından araştırma sorusunun yanıtlanmasında Pearson korelasyon analizine başvurulmuştur. Bu analize ilişkin bulgular Tablo 2'de sunulmuştur.

Tablo 2.

GKK ile PİK Alt Boyutları Arasındaki İlișki

\begin{tabular}{|c|c|c|c|c|}
\hline $\mathrm{n}=538$ & Aşırı kullanım & Sosyal fayda & $\begin{array}{l}\text { Olumsuz } \\
\text { sonuçlar }\end{array}$ & GKK \\
\hline Aşırı kullanım & - & $0.40 * *$ & $0.50 * *$ & $0.24 * *$ \\
\hline Sosyal fayda & $0.40 * *$ & - & $0.80 * *$ & $0.46^{* *}$ \\
\hline $\begin{array}{l}\text { Olumsuz } \\
\text { sonuçlar }\end{array}$ & $0.50 * *$ & $0.80 * *$ & - & $0.42 * *$ \\
\hline GKK & $0.24 * *$ & $0.46 * *$ & $0.42 * *$ & - \\
\hline
\end{tabular}

**Korelasyon 0.01 düzeyinde anlamlıdır.

Tablo 2'de görüldüğü gibi GKK ve PİK'nın bütün alt boyutları arasındaki ilişkiler anlamlıdır $(\mathrm{p}<0.01)$. Sözü edilen ilişkilerin istatistiksel olarak anlamlı olup olmadığının yanı sıra yönü ve ilişki düzeyi de incelenmelidir. Bütün ilişki katsayılar pozitif olduğundan ( $r>0$ ) değişkenleri arasındaki her bir ilişkinin pozitif yönde olduğu görülmektedir. Cohen'e (1988) göre $r$ değeri 0.10 ile 0.29 arası düşük, 0.30 ile 0.49 arası orta, 0.50 ile 1.00 arasında ise yüksek ilişkiden söz edilmelidir. Buna göre, PİK'nın alt boyutlarının kendi aralarındaki ilişkiler irdelendiğinde; aşırı kullanım alt boyutu ile sosyal fayda alt boyutu arasında $(r=0.40)$ orta düzeyde; aşırı kullanım alt boyutu ile olumsuz sonuçlar alt boyutu arasında $(\mathrm{r}=0.50)$ ve sosyal fayda alt boyutu ile olumsuz sonuçlar alt boyutu arasında $(\mathrm{r}=0.80)$ yüksek düzeyde ilişki gözlemlenmiştir. Araştırma sorusuna yanıt olarak, GKK ve PİK'nın alt boyutları arasındaki ilişki incelendiğinde GKK ile aşırı kullanım alt boyutu düşük $(\mathrm{r}=0.24)$ bir ilişki gözlemlenmektedir. GKK ile sosyal fayda alt boyutu arasında $(\mathrm{r}=0.46)$ ve GKK ile olumsuz sonuçlar alt boyutu arasında $(\mathrm{r}=0.42)$ orta düzeyde bir ilişki gözlemlenmektedir.

PİK gibi birden fazla alt boyuttan oluşan yapılarda alt boyutların birbiri ile orta düzeyde bir ilişki göstermesi beklenmektedir. Eğer birbirinden bağımsız, başka bir ifade ile ilişkisiz alt boyutlar söz konusu ise burada alt boyutların kuramsal bağlamda nasıl bir araya getirildiklerinin gözden geçirilmesi gerekmektedir. Öte yandan birbiri ile çok yüksek düzeyde ilişkili olan alt boyutlar ise tek değişken gibi davranma eğiliminde olduklarından birleştirilmesi gerekliliği doğmaktadır (Pallant, 2001). Bu bilgi ve çalışma kapsamında ortaya çıkarılan ilişkilerin anlamlı, düşük ve orta düzeyde olması göz önüne alındığında, GKK'nın PİK'nın bir alt boyutu olarak düşünülebileceği söylenebilir. Bu hipotez ayrı bir araştırma sorusu olarak ele alınmış ve doğruluğu doğrulayıcı faktör analizi ile test edilmiştir.

\section{GKK, PIK'nın bir alt boyutu olarak anlamlı mıdır?}

$\mathrm{Bu}$ araştırma sorusu doğrulayıcı faktör analizi ile yanıtlanmıştır. Hazırda üç faktörden oluşan PİK'nın bir alt boyutu olarak düşünülmek üzere dördüncü faktör olarak GKK eklenmiş ve bu biçimi ile yapının doğrulandığı görülmüştür. Daha açık bir ifade ile PİK'nın bu araştırma çerçevesinde dört boyutlu olduğu öne sürülmüsstür. Öne sürülen bu yapıya ilişkin yol diyagramı Şekil 1'de sunulmuştur. 


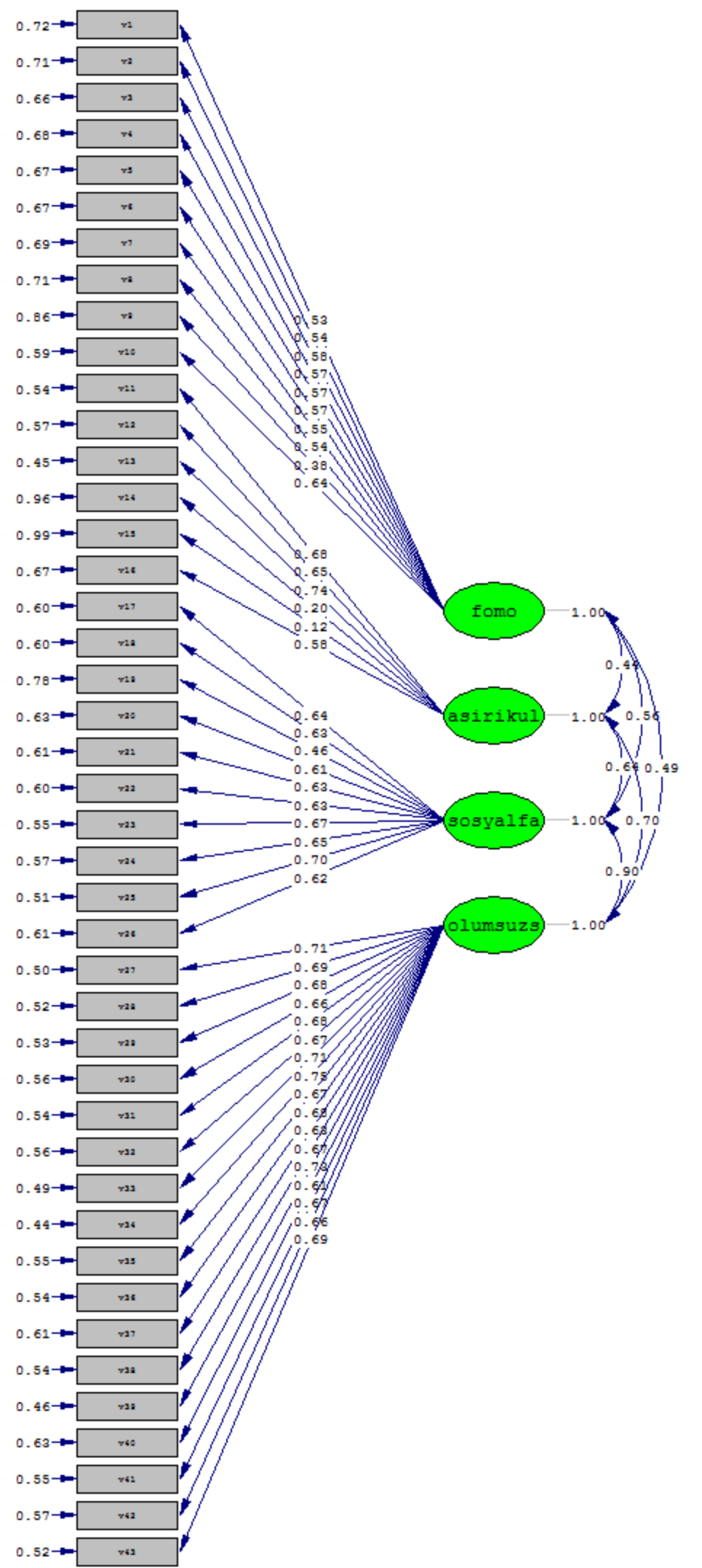

Şekil 1. GKK, PİK'nın Bir Alt Boyutu Olarak Düşünüldügünde Oluşan Yol Diyagramı 
Şekil 1'de sunulan yol diyagramında tanımlanan bütün yollar anlamlıdır. Görüldüğü gibi yolların herhangi birini hatalı renkte oluşmamıştır. Gözlenen $\chi^{2}$ ve serbestlik derecesinin yüksek olmasının nedeni analizin 538 kişinin yanıtından oluşturulan veri seti ile yürütülmesidir $\left(\chi^{2}=1870.52 ; \mathrm{sd}=854\right)$. Bu durum araştırma kapsamında öne sürülen yapının doğruluğuna ilişkin ilk bulgudur. Yol diyagramının incelenmesinin ardından, gerçekleştirilen analiz çıktılarında t ve $\mathrm{R}^{2}$ değerleri incelenmiştir. Sözü edilen değerler Tablo 3’te sunulmuştur.

Tablo 3.

PİK'nın GKK Eklenerek Oluşturulan Dört Faktörlü Yapısının t ve $\mathrm{R}^{2}$ Değerleri

\begin{tabular}{|c|c|c|c|}
\hline Faktör ad1 & Madde numaraları & $\mathrm{t}$ değerleri & $\mathrm{R}^{2}$ \\
\hline \multirow[t]{10}{*}{ GKK } & GKK-1 & 10.51 & 0.28 \\
\hline & GKK-2 & 10.59 & 0.29 \\
\hline & GKK-3 & 11.65 & 0.34 \\
\hline & GKK-4 & 11.32 & 0.32 \\
\hline & GKK-5 & 11.43 & 0.33 \\
\hline & GKK-6 & 11.49 & 0.33 \\
\hline & GKK-7 & 11.00 & 0.31 \\
\hline & GKK-8 & 10.63 & 0.29 \\
\hline & GKK-9 & 7.14 & 0.14 \\
\hline & GKK-10 & 13.26 & 0.42 \\
\hline \multirow[t]{6}{*}{ Aşırı kullanım } & PİK-1 & 13.89 & 0.46 \\
\hline & PİK-2 & 13.30 & 0.42 \\
\hline & PİK-6 & 15.53 & 0.55 \\
\hline & PİK-7 & 3.59 & 0.04 \\
\hline & PİK-12 & 2.15 & 0.01 \\
\hline & PİK-30 & 11.43 & 0.33 \\
\hline \multirow[t]{10}{*}{ Sosyal fayda/sosyal rahatlik } & PİK-3 & 13.70 & 0.40 \\
\hline & PİK-4 & 13.57 & 0.40 \\
\hline & PİK-5 & 9.42 & 0.22 \\
\hline & PİK-8 & 13.00 & 0.37 \\
\hline & PİK-10 & 13.49 & 0.39 \\
\hline & PİK-11 & 13.51 & 0.40 \\
\hline & PİK-13 & 14.75 & 0.45 \\
\hline & PİK-26 & 14.18 & 0.43 \\
\hline & PİK-32 & 15.43 & 0.49 \\
\hline & PİK-33 & 13.33 & 0.39 \\
\hline \multirow[t]{17}{*}{ İnternetin olumsuz sonuçları } & PİK-9 & 16.12 & 0.50 \\
\hline & PİK-14 & 15.64 & 0.48 \\
\hline & PİK-15 & 15.29 & 0.47 \\
\hline & PİK-16 & 14.67 & 0.44 \\
\hline & PİK-17 & 15.23 & 0.46 \\
\hline & PİK-18 & 14.79 & 0.44 \\
\hline & PİK-19 & 16.26 & 0.51 \\
\hline & PİK-20 & 17.28 & 0.56 \\
\hline & PİK-21 & 14.94 & 0.45 \\
\hline & PİK-22 & 15.27 & 0.47 \\
\hline & PİK-23 & 13.67 & 0.39 \\
\hline & PİK-24 & 15.05 & 0.46 \\
\hline & PİK-25 & 16.84 & 0.54 \\
\hline & PİK-27 & 13.11 & 0.37 \\
\hline & PİK-28 & 14.99 & 0.45 \\
\hline & PİK-29 & 14.61 & 0.44 \\
\hline & PİK-31 & 15.65 & 0.48 \\
\hline
\end{tabular}


Tablo 3'te sunulan $t$ değerlerinin 2.15 ile 17.28 arasında değiştiği görülmektedir. Bütün t değerleri anlamlıdır $(\mathrm{p}<0.001)$ ve yol diyagramında hata oluşturmamıştır. Bununla birlikte $\mathrm{R}^{2}$ değerleri incelendiğinde 0.01 ile 0.56 arasında değiştiği görülmüsstür. Alanyazında iki ya da daha fazla faktörden oluşan yapılar için madde yüklerinin 0.32 ve üzeri bir değerde olmasının yeterli olduğu (Costello ve Osborne, 2005) öne sürülmüştür. Analiz edilen toplam 43 maddenin sekizinin $\mathrm{R}^{2}$ değerleri 0.32 'den küçük, geriye kalan 35 maddenin ilgili değeri 0.32 'den büyüktür. $\mathrm{Bu}$ durum; geliştirilen ölçeklerin temalarının teknoloji olması ve teknolojinin dönemsel değişimlere uğraması nedeniyle maddelerin bazılarının değiştirilmesi ve güncellenmesi gerektiği şeklinde yorumlanabilir. Ancak ölçek maddelerinin büyük bir çoğunluğunun (\%81.4) sözü edilen değerinin 0.32'nin üzerinde olması büyük oranda başarıya ulaşıldığını gösterebilir. Schreiber, Nora, Stage, Barlow ve King (2006) $\mathrm{R}^{2}$ değerleri yerine yol katsayılarının yorumlanmasının daha doğru olduğunu öne sürmektedir. Bu noktadan hareketle yol katsayılarından biri olan t değerlerinin anlamlı olması, çalışma kapsamında öne sürülen yapının doğrulandığının bir diğer göstergesi sayılabilir. Son olarak, doğrulayıcı faktör analizi kapsamında hesaplanan uyum değerleri incelenmiştir. Bu değerler Tablo 4 'te sunulmuştur.

Tablo 4.

PİK'nın GKK Eklenerek Oluşturulan Dört Faktörlü Yapısının Doğrulayıcı Faktör Analizi Uyum Değerleri

\begin{tabular}{lllll}
\hline Uyum İndeksi & En İyi Uyum Değeri & Kaynak & $\begin{array}{l}\text { Ölçülen } \\
\text { Değeri }\end{array}$ & Uyum \\
\hline$\chi^{2} / \mathrm{sd}$ & $0 \leq \chi^{2} / \mathrm{sd} \leq 3$ & $($ Kline, 2005) & 2.19 \\
$\mathrm{p}$ & $.05 \leq \mathrm{p} \leq 1.00$ & (Hoyle, 1995) & $<0.001$ \\
RMSEA & $0.05 \leq \mathrm{RMSEA} \leq 0.10^{*}$ & (Jöreskog ve Sörbom, 1993) & 0.06 \\
SRMR & SRMR $\leq 0.08$ & (Kenny, 2010) & 0.07 \\
NFI & $.80 \leq \mathrm{NFI} \leq 1$ & (Kenny, 2010) & 0.95 \\
CFI & $.95 \leq \mathrm{CFI} \leq 1$ & (Hu ve Bentler, 1999) & 0.97 \\
GFI & $.80 \leq \mathrm{GFI} \leq 1$ & (Bluch, 2008) & 0.80 \\
\hline$\chi^{2}=1870.52 ; \mathrm{sd}=854$ & & & \\
\hline
\end{tabular}

*Kabul edilebilir uyum değerini göstermektedir.

Tablo 4'te sunulan uyum değerleri, öne sürülen yapı ile analiz işleminde üretilen en iyi yapı arasındaki uygunluğu istatistiksel olarak değerlendirmektedir. Başka bir ifade ile araştırmacı tarafından önerilen yapı ile ideal yapı arasındaki uyumu bu değerler göstermektedir. Buradan hareketle doğrulayıcı faktör analizinde uyum değerlerinin alanyazında belirtilen aralıklarda olmasının, yapının doğrulandığına yönelik en önemli kanıt olduğu söylenebilir. Tabloda görüldüğ̈̈ gibi GKK Pİ'nın bir alt boyutu olarak düşünülerek oluşturulan yapının RMSEA dışındaki uyum değerleri en iyi uyum değeri aralığındadır. RMSEA değeri ise kabul edilebilir bir uyum değerine sahiptir. Buradan hareketle GKK'nun PİK kullanımının istatistiksel olarak anlamlı bir alt boyutu olduğu söylenebilir.

\section{Sonuç ve Tartışma}

Araştırma kapsamında elde edilen sonuçlardan ilki GKK'nun PİK'nın alt boyutlarının tamamı ile anlamlı ve pozitif yönde ilişkilerinin olduğudur. PİK'nın alt boyutlarının kendi aralarındaki ilişkiler irdelendiğinde; aşırı kullanım alt boyutu ile sosyal fayda alt boyutu arasında $(\mathrm{r}=0.40)$ orta düzeyde; aşırı kullanım alt boyutu ile olumsuz sonuçlar alt boyutu arasında $(\mathrm{r}=0.50)$ ve sosyal fayda alt boyutu ile olumsuz sonuçlar alt boyutu arasında $(\mathrm{r}=0.80)$ yüksek düzeyde ilişki gözlemlenmiştir. Araştırma sorusuna yanıt olarak, GKK ve PİK'nın alt boyutları arasındaki ilişki incelendiğinde GKK ile aşırı kullanım alt boyutu düşük $(r=0.24)$ bir ilişki gözlemlenmektedir. GKK ile sosyal fayda alt boyutu arasında $(r=0.46)$ ve GKK ile olumsuz sonuçlar alt boyutu arasında $(r=0.42)$ orta düzeyde bir ilişki gözlemlenmektedir. Bu ilişkinin temel kaynağının her iki olgunun internet kullanımı davranışı üzerine temellenmesi olduğu 
düşünülmektedir. Bununla birlikte, her iki davranış da yoksunluk belirtileri, yalnızlık hissi, sevgi gereksiniminin tatmini gibi noktalarda birbiriyle benzer göstergelere sahiptir. İstatistiksel olarak kanıtlanan bu ilişki kuramsal bağlamda da ifade edilmiş bir durumdur. İlişkilerin yüksek düzeyde olmamasının, kavramların benzerliklerinin yanı sıra PİK'nın daha geniş kapsamlı bir kavram olmasından kaynaklandığı düşünülmektedir. Daha açık bir ifade ile PİK sosyal medya kullanımı sırasında da gözlenebilir ancak internet aracılığı ile kullanılan kumar, zorbalık vs. gibi başka kavramları da kapsamaktadır. Oysa GKK sosyal medya ile sınırlı bir olgudur. Bu nedenle ilişkinin kuramsal anlamda da çalışma kapsamında kanıtlandığı düzeyde olduğu söylenebilir.

Alanyazında PİK, internet bağımlılı̆̆ı, sosyal medya bağımlılı̆̆ kavramlarının ilişkili olduğuna yönelik çalışmalar bulunmaktadır (Çam ve İşbulan, 2012; Lin, Ko ve Wu, 2011; Schimmenti, Passanisi, Gervasi, Manzella ve Fama, 2014). Elhai, Levine, Dvorak ve Hall (2016), GKK ile akıllı telefon bağımlılığı arasında anlamlı, pozitif yönde ve orta düzeyde bir ilişki olduğunu öne sürmüşlerdir $(\mathrm{r}=0.40 ; \mathrm{p}<0.001)$. Gökler ve diğerleri, (2016), cep telefonu problemli kullanımı ile GKK arasında anlamlı, pozitif yönde ve yüksek düzeyde bir ilişki bulunduğunu saptamışlarıdır $(r=0.587, p<0.001)$. Blackwell ve diğerleri (2017) ise çalışmalarında GKK ile sosyal medya bağımlılığı arasında anlamlı, pozitif yönde ve yüksek düzeyde bir ilişki olduğunu $(r=0.56 ; p<0.01)$ ortaya çıkarmışlardır. Stead ve Bibby (2017) ise çalışmalarında GKK ile PİK arasında anlamlı, pozitif yönde ve orta düzeyde iliş̧ki bulmuşlardır. $\mathrm{Bu}$ bilgilerden hareketle araştırmada ortaya çıkarılan GKK ve PIK'nın bütün alt boyutları arasındaki ilişkilerin alanyazında sunulan bilgiler ile paralellik gösterdiği söylenebilir.

Çalışma kapsamında elde edilen bir diğer sonuç GKK'nun PİK'nın bir alt boyutu olarak düşünülebileceğidir. Bu durum doğrulayıc faktör analizi ile iki ölçeğin maddelerinin birlikte tek ölçek gibi faktör yapısı olabileceği düşünüldüğünde anlamlı bir yapının ortaya çıktığı bulgusu ile ortaya konmuştur $\left(\chi^{2} / \mathrm{sd}=2.19, \mathrm{p}<0.001\right.$, RMSEA $=0.06$, SRMR $=0.07, \mathrm{NFI}=0.95, \mathrm{CFI}=$ $0.97, \mathrm{GFI}=0.80$ ). Alanyazında GKK ile PIKK ya da ilişkili problemli kullanım davranışlarını birlikte analiz eden yapısal eşitlik modeli ile şekillendirilmiş bir çalışmaya rastlanmamıştır. Yapısal eşitlik modelleme analizlerinin, regresyon analizi gibi ilişki katsayıları hesaplamalarından yol çıkarak bir model denediği (Çelik ve Yılmaz, 2013, s. 6; Kline, 2005) göz önünde bulundurularak, alanyazında ilgili regresyon modelleri incelenmiştir.

Elhai ve diğerleri (2016) çalışmalarında yaş, cinsiyet, depresyon, kaygı, duygusal değerleme, duygusal baskı, GKK gibi değişkenlerin akıllı telefon bağımlılı̆̆ını yordayıcılıklarına yönelik bir model önermişlerdir. Sözü edilen çalışmada GKK'nun akıllı telefon bağımlılı̆̆ının en yüksek yordayıcısı olduğu bulunmuştur. Blackwell ve diğerleri (2017) dışadönüklük, duygusal dengesizlik, kaçınma, kaygı ve GKK ölçümlerinin sosyal medya kullanımı ve sosyal medya bağımlılı̆̆ını yordayıcılıklarını araştırmışlardır. Sözü edilen çalışmanın sonucunda hem sosyal medya kullanımının hem de sosyal medya bağımlılı̆̆ının en yüksek yordayıcısının GKK olduğu ortaya çıkarılmıştır. Vaidya, Jaiganesh ve Krishnan (2016) çalışmalarında internet bağımlılığı ve GKK arasındaki ilişkiyi bireylerin bu davranışlara yönelik ölçümleri üzerinden betimsel olarak incelemişlerdir. Sözü edilen çalışmanın katılımcılarının çok az bir bölümü (\%2.67) GKK davranış1 göstermeksizin internet bağımlısı olduğu, internet bağımlısı olmayan ancak GKK gösteren katılımc1 oranı ise \%24 olduğu bulunmuştur. Geriye kalan katılımcılar (\%73.33) ise hem internet bağımlısı hem de GKK davranışı göstermektedir. Bu durum GKK'nun internet bağımlılığının ve eş anlamlı olarak kullanılan PİK'nın alt boyutu olduğuna yönelik bir göstergedir. Tüm bu bilgiler ışı̆̆ında, bu çalışmanın GKK'nun PİK'nın bir alt boyutu olarak ele alınarak tanımlanan yolların anlamlı olması ve alanyazında yürütülmüş çalışmalar arasında tutarlılık görülmektedir. Bununla birlikte bu çalışma, alanyazında var olmayan GKK ve PIK arasındaki ilişkinin yapısal eşitlik modellemesi ile incelenmesi bakımından özgündür.

Araştırma sonucunda GKK olgusunun PİK ile birlikte düşünülebileceği sonucuna ulaşılmıştır. Kuramsal bağlamda GKK; sosyal medya uygulamalarının internet bağlantısı ile kullanılması, bağımlılık göstergeleri ortaya çıkarması, günlük yaşantıyı olumsuz yönde etkilemesi gibi noktalarda PİK ile ilişkilidir. Ancak bu ilişkinin istatistiksel bağlamda anlamlı olur olmadığına yönelik alanyazında bir çalışma bulunmamaktadır. Bu çalışma ile PİK'nın 
kapsamının değiştiği ve güncellenmesi gerekliliği ortaya çıkarılmışır denebilir. En genel anlamda PİK olgusunun değişime uğradığı ve çeşitli açılardan yeniden incelenmesi gerektiği söylenebilir. Bununla birlikte alanyazında son dönemde tartışılan ve kavramsal olarak her geçen gün artan siber suçların her biri de PİK çerçevesinde incelenebileceği düşünülmektedir. Buradan hareketle PİK ile birlikte internet bağımlılığı, teknostres, aşırı internet kullanımı gibi olguların da istatistiksel bağlamda birlikte incelenmesi gerektiği söylenebilir. Dönüşen PİK olgusu yeniden ele alınarak güncellenebilir.

\section{Kaynaklar}

Alt, D. (2015). College students' academic motivation, media engagement and fear of missing out. Computers in Human Behavior, 49, 111-119.

Altunışık, R., Coşkun, R., Bayraktaroğlu, S. ve Yıldırım, E. (2012). Sosyal bilimlerde araştırma yöntemleri: SPSS uygulamalı (7. baskı). İstanbul: Sakarya Yayıncılık.

Blackwell, D., Leaman, C., Tramposch, R., Osborne, C. ve Liss, M. (2017). Extraversion, neuroticism, attachment style and fear of missing out as predictors of social media use and addiction. Personality and Individual Differences, 116, 69-72.

Blunch, N. J. (2008). Introduction to structural equation modelling: Using SPSS and AMOS. Los Angeles: Sage Publications.

Büyüköztürk, Ş., Kılıç Çakmak, E., Akgün, Ö. E., Karadeniz, Ş. ve Demirel, F. (2018). Bilimsel araştırma yöntemleri (24. baskı). Ankara: Pegem Akademi.

Ceyhan, A. A. (2008). Predictors of problematic internet use on Turkish university students. CyberPsychology \& Behavior, 11(3), 363-366.

Ceyhan, E. (2010). Predictiveness of identity status, main internet use purposes and gender on university students' the problematic internet use. Educational Sciences: Theory and Practice, 10(3), 1343-1355.

Ceyhan, E., Ceyhan, A. A. ve Gürcan, A. (2007). Problemli İnternet Kullanımı Ölçeği'nin geçerlik ve güvenirlik çalışmaları. Kuram ve Uygulamada Eğitim Bilimleri, 7(1), 387416.

Chou, C. ve Hsiao, M. C. (2000). Internet addiction, usage, gratification, and pleasure experience: the Taiwan college students' case. Computers \& Education, 35(1), 65-80.

Cohen, J. W. (1988). Statistical power analysis for behavioral sciences (2. bask1). Hillsdale, NJ: Lawrence Erlbaum Associates.

Costello, A. B. ve Osborne, J. W. (2005). Best practices in exploratory factor analysis: Four recommendations for getting the most from your analysis. Practical Assessment, Research and Evaluation, 10(7), 1-9.

Çam, E. ve İşbulan, O. (2012). A new addiction for teacher candidates: Social networks. Turkish Online Journal of Educational Technology-TOJET, 11(3), 14-19.

Çelik, H. E. ve Y1lmaz, V. (2013). LISREL 9.1 ile yapısal eşitlik modellemesi: Temel kavramlar, uygulamalar, programlama (Yenilenmiş 2. baskı). Ankara: Anı Yayınc1lı.

Çokluk, Ö., Şekercioğlu, G. ve Büyüköztürk, Ş. (2012). Sosyal bilimler için çok değişkenli istatistik: SPSS ve LISREL uygulamaları (2. baskı). Ankara: Pegem Akademi.

Davis, R. A. (2001). A cognitive-behavioral model of pathological Internet use. Computers in Human Behavior, 17(2), 187-195.

Dossey, L. (2014). FOMO, digital dementia, and our dangerous experiment. Explore: The Journal of Science and Healing, 10(2), 69-73.

Elhai, J. D., Levine, J. C., Dvorak, R. D. ve Hall, B. J. (2016). Fear of missing out, need for touch, anxiety and depression are related to problematic smartphone use. Computers in Human Behavior, 63, 509-516.

Gökler, M. E., Aydın, R., Ünal, E. ve Metintaş, S. (2016). Sosyal ortamlarda gelişmeleri kaçırma korkusu ölçeğinin Türkçe sürümünün geçerlilik ve güvenilirliğinin değerlendirilmesi. Anadolu Psikiyatri Dergisi, 17(1), 52-59.

Griffiths, M. (1996). Internet addiction: An issue for clinical psychology? Clinical Psychology Forum, 97, 32-36. 
Griffiths, M. (2000). Internet addiction: Time to be taken seriously? Addiction Research, 8, 413418.

Hato, B. (2013). Mobile phone checking behavior out of a fear of missing out: Development, psychometric properties and test-retest reliability of a C-FoMO-Scale ANR: 610304. (Yayımlanmamış yüksek lisans tezi).

Hetz, P. R., Dawson, C. L. ve Cullen, T. A. (2015). Social media use and the fear of missing out (FoMO) while studying abroad. Journal of Research on Technology in Education, 47(4), 259-272.

Hoyle, R. H. (1995). Structural equation modeling: Concepts, issues, and applications. London: Sage Publications.

Hu, L. ve Bentler, P. M. (1999). Cutoff criteria for fit indexes in covarience structure analysis: Conventional criteria versus new alternatives. Structural Equation Modeling, 6, 1-55.

Huck, S. W. (2012). Reading statistics and research (6. baskı). Boston: Pearson.

Jöreskog, K. G. ve Sörbom, D. (1993). Lisrel 8: Structural equation modeling with simplis command language. Lincolnwood: Scientific Software International.

Kenny, D. A. (2010). Measuring model fit. Erişim adresi: davidakenny.net $/ \mathrm{cm} / \mathrm{fit}$.htm

Kline, R. B. (2005). Principles and practice of structural equation modeling (2. bask1). NY: Guilford Publications.

Krishnamurthy, S. ve Chetlapalli, S. K. (2015). Internet addiction: Prevalence and risk factors: A cross-sectional study among college students in Bengaluru, the Silicon Valley of India. Indian journal of public health, 59(2), 115.

Kuss, D. J. ve Griffiths, M. D. (2011). Online social networking and addiction- A review of the psychological literature. International Journal of Environmental Research and Public Health, 8(9), 3528-3552.

Leung, L. (2004). Net-generation attributes and seductive properties of the internet as predictors of online activities and internet addiction. CyberPsychology \& Behavior, 7(3), 333-348.

Li, Q. (2006). Cyberbullying in schools: A research of gender differences. School Psychology International, 27(2), 157-170.

Li, S. M. ve Chung, T. M. (2006). Internet function and internet addictive behavior. Computers in Human Behavior, 22(6), 1067-1071.

Lin, M. P., Ko, H. C. ve Wu, J. Y. W. (2011). Prevalence and psychosocial risk factors associated with internet addiction in a nationally representative sample of college students in Taiwan. Cyberpsychology, Behavior and Social Networking, 741-746.

Morford, M. (2010). Oh my God you are so missing out. Erişim adresi:www.sfgate.com/entertainment/morford/article/Oh-my-God-you-areso-missingout-2536241.php

Özdamar, K. (2013). Paket programlar ile istatistiksel veri analizi (Yenilenmiş 9. bask1, Cilt 1). Ankara: Nisan Kitabevi.

Öztürk, Ö., Odabaşığlu, G., Eraslan, D., Genç, Y. ve Kalyoncu, Ö. A. (2007). İnternet bağımlılığı: Kliniği ve tedavisi. Bağımlılık Dergisi, 8(1), 36-41.

Pallant, J. (2001). SPSS survival manual: A step by step guide to data analysis using SPSS for Windows: SPSS student version 11.0 for Windows. Milton Keynes: Open University Press.

Przybylski A. K., Murayama K., DeHaan C. R. ve Gladwell, V. (2013). Motivational, emotional, and behavioral correlates of fear of missing out. Computers in Human Behavior, 29(4), 1841-1848.

Reagle, J. (2015). Following the Joneses: FOMO and conspicuous sociality. First Monday, 20(10). Erişim adresi: journals.uic.edu/ojs/index.php/fm/article/view/6064/4996

Sadi, S., Şekerci, A., Kurban, B., Topu, F., Demirel, T., Tosun, C., Demirci, T. ve Göktaş, Y. (2008). Öğretmen eğitiminde teknolojinin etkin kullanımı: Öğretim elemanları ve öğretmen adaylarının görüşleri. Bilişim Teknolojileri Dergisi, 1(3), 43-49.

Sani-Bozkurt, S. (2017). Özel eğitimde dijital destek: Yardımcı teknolojiler. Açıköğretim Uygulamaları ve Araştırmaları Dergisi, 3(2), 37-60. 
Schimmenti, A., Passanisi, A., Gervasi, A. M., Manzella, S. ve Fama, F. I. (2014). Insecure attachment attitudes in the onset of problematic internet use among late adolescents. Child Psychiatry and Human Development, 45(5), 588-595.

Schreiber, J. B., Nora, A., Stage, F. K., Barlow, E. A. ve King, J. (2006) Reporting structural equation modeling and confirmatory factor analysis results: A review. The Journal of Educational Research, 99(6), 323-338.

Sönmez, V. ve Alacapınar, F. G. (2013). Örneklendirilmiş bilimsel araştırma yöntemleri (2. bask1). Ankara: Anı Yayıncılık.

Spraggins, A. (2009). Problematic use of online social networking sites for college students: Prevalence, predictors, and association with well-being. Gainesville: University of Florida.

Stead, H. ve Bibby, P. A. (2017). Personality, fear of missing out and problematic internet use and their relationship to subjective well-being. Computers in Human Behavior, 76, 534540.

Şencan, H. (2005). Sosyal ve davranışsal ölçümlerde güvenilirlik ve geçerlilik. Ankara: Seçkin Yayınc1lık.

Tabachnick, B. G. ve Fidell, L. S. (2013). Using multivariate statistics (6. baskı). Pearson: ABD.

Taş, G. (2015). Sosyal medya tarihçesi. Erişim adresi:www.dijitalajanslar.com/sosyal-medyatarihcesi/

Tsai, C. C. ve Lin, S. S. J. (2001). Analysis of attitudes toward computer networks and internet addiction of Taiwanese adolescents. Cyberpsychology \&Behavior, 4, 373-376.

Vaidya, N., Jaiganesh, S. ve Krishnan, J. (2016). Prevalence of Internet addiction and its impact on the physiological balance of mental health. National Journal of Physiology, Pharmacy and Pharmacology, 6(1), 97-100.

Varol, F. ve Yıldırım, E. (2017). Siberaylaklık: Öğretmen adayları ve mobil teknolojiler. Mersin University Journal of the Faculty of Education, 13(3), 1046-1057.

Young, K. S. (1998). Internet addiction: The emergence of a new clinical disorder. Cyberpsychology \& Behavior, 1(3), 237-244.

\section{Extended Abstract}

\section{Introduction}

Problematic internet use (PIU) is one of the most comprehensive cyber/digital behavioral concepts in literature. Internet addiction, pathological internet use, excessive internet use concepts are frequently used as synonymous with PIU. In general, PIU was defined as using internet in a detrimental way during daily, personal professional and social activities. PIU is a concept that widens the scope 1900s when first times PIU named and defined until these days. At the beginning, PIU was explained and examined with other problematic concepts such as technology addiction, internet addiction, and virtual gambling (Davis, 2001; Griffiths, 1996; Li \& Chung, 2006; Tsai \& Lin, 2003). And then, these behaviors classified in their own frame according to different behavior characteristics. For instance, technology addiction was classified as smart phone addiction, screen addiction, media addiction etc. As well, the problematic behaviors such as social media addiction, cyber laughing, cyber-crimes etc. were defined under the frame of internet addiction.

The reasons of problematic internet use can be that accessing internet is so easy and broaden social media tools (Kuss \& Griffiths, 2011). From this point of views, it can be said that the purpose of internet use and the outputs of these uses are important determining people PIU. While people used internet for academic purposes in the earlier time, they use the internet for social media and communication at these days (Ceyhan, 2010). Along with social media tools became widespread, the following and updating frequentative behaviors, the others have fun more than when they are together anxiety of social network users in particular the young was defined as fear of missing out (FoMO). In literature, it was stated that FoMO has 
relationships with not only using social media but also obsessive and unhealthy behaviors, problematic and addicted internet use (Stead \& Bibby, 2017).

As mentioned below, FoMO and PIU share some similarities such as the need of internet connection, meeting the need of being liked in online platforms, deprivation, defining as a problematic behavior. From this point of view, it was wondered whether PIU a comprehensive concept which is involved FoMO or not, in other words FoMO is a sub-dimension of PIU or not. Any research, which was proved this relationship statistically, could not be found. The general frame of the research, conducted for meeting the need of literature at this context, is to prove theoretical relationship between FoMO and PIU within statistic. The main purposes of this study are to reveal the relationship between FoMO and PIU. For this purpose it was tried to answer following listed research questions;

1. Is there a significant relationship between FoMO and PIU? If there is, what are its level and directions?

2. Whether FoMO is a sub-dimension of PIU or not?

\section{Methods}

During this research, the process was conducted in the frame of correlational survey research model. For this study, the data were gathered via PIU scale developed by Ceyhan, Ceyhan and Gürcan (2007) and FoMO scale developed by Gökler, Aydın, Ünal and Metintaş (2016) from 538 undergraduate students who are educating different faculties of a state university in Turkey at 2017-2018 academic year spring semester. Being varied participants with regards to demographic variables can be an indicator that the sample can be generalized to the population. Data gathering process was conducted by the researcher and guarantied voluntary participation.

At the beginning of data analysis process, the preconditions of parametric tests (continuous variables, normal distribution etc.) were checked. Skewness values (between the range of 0.087 and 0.811 ) an kurtosis values (between the range of -0.277 and 0.207 ) of the research data were examined and it was seen that whole values of variables were between the range of +1 and -1 , so it can be said that they were distributed normally (Huck, 2012, p. 27). Because the preconditions were fulfilled, the findings were created as conducted Pearson correlation analysis and structural equation modelling.

\section{Result and Discussion}

First of the results is that there are significant and positive relationships among FoMO and all of the PIU sub-dimensions. Besides mentioned relationships' direction and whether they are significant or not, their level has to examine as well. If $r$ value is in the range of 0.10 and 0.29 , the correlation level is low, if $r$ value is in the range of 0.30 and 0.49 , it is medium, $r$ value is in the range of 0.50 and 1.00, and it is high. According to this information, when the relationships among PIU's sub-dimensions each other were evaluated, mid-level relationship was seen between excessive use sub-dimension and social benefit/ social comfort sub-dimension ( $\mathrm{r}=$ 0.40 ). The high level relationships were seen between excessive use sub-dimension and negative consequences of internet sub-dimension $(r=0.50)$ and between social benefit/ social comfort sub-dimension and negative consequences of internet sub-dimension $(r=0.80)$. To answer research question, when the relationships among FoMO and PIU's sub-dimensions were evaluated, low-level relationship was seen between FoMO and excessive use sub-dimension ( $\mathrm{r}=$ 0.24). The mid-level relationships were seen between FoMO and social benefit/ social comfort sub-dimension $(\mathrm{r}=0.46)$ and between FoMO and negative consequences of internet subdimension $(\mathrm{r}=0.42)$.

It is thought that the main reason of these relationships is both concepts are based on internet problematic use. Besides, PIU can be observed during social media use as well as FoMO, but PIU involves some other concepts related with internet use such as gambling, cyberbullying etc. Whereas, FoMO is a concept limited with social media use. For this reason, it can be said that the level of relationships are similar theoretically. In literature, there are researches which reveal the relationship among PIU and internet addiction, social media 
addiction (Çam \& İşbulan, 2012; Lin, Ko \& Wu, 2011; Schimmenti, Passanisi, Gervasi, Manzella \& Fama, 2014). From the view of these researches it can be said that the results of this study are parallel with previous studies in literature.

The other result is that FoMO could be examined as a sub-dimension of PIU. This situation was proved via confirmatory factor analysis defined the paths of FoMO and its items as sub-dimension of PIU $\left(\chi^{2} / \mathrm{df}=2.19, \mathrm{p}<0.001, \mathrm{RMSEA}=0.06, \mathrm{SRMR}=0.07, \mathrm{NFI}=0.95, \mathrm{CFI}=\right.$ $0.97, \mathrm{GFI}=0.80$ ). Additionally, defined paths were significant, $\mathrm{t}$ values were significant and had no error and most of $\mathrm{R}^{2}$ values (81.4\%) were efficient. The obtained results were discussed and compared with related studies. 